\title{
The Relevance of Stability and Change of Achievement Goals for Self-regulated Motor Learning Processes and Outcomes
}

\author{
Martin Daumiller \\ University of Augsburg
}

\author{
Raven Rinas \\ University of Augsburg
}

\author{
David Jaitner \\ University of Braunschweig
}

\begin{abstract}
Self-regulated motor learning is a frequent and important achievement activity in sport and exercise contexts. Therein, individual learners' achievement goals can be considered relevant for motor learning processes and outcomes. To better understand their role, we first examined the temporal stability of achievement goals during self-regulated motor learning. Next, we tested the relevance of the goals and their temporal variability for the learning process (learning time, effort, and motivational problems) and learning outcomes (performance and continuance intentions). To this end, 93 individuals completed a total of 1,017 daily diary entries about their goals (learning-approach, performance-approach, performance-avoidance, work-avoidance goals) and learning processes across sixteen days while learning juggling basics. Afterwards, they completed a post-test assessing their learning outcomes. Multi-level analyses indicated that goals contained both temporally stable and temporally variable fractions that were both relevant for learning processes. For learning outcomes, not only mean levels, but also temporal trends mattered.
\end{abstract}

Keywords: achievement goals; motor learning; goals orientations; mastery; ability

(C) 2021, American Psychological Association. The official citation for this manuscript is: Daumiller, M., Rinas, R., \& Jaitner, D. (2021). The Relevance of Stability and Change of Achievement Goals for Self-regulated Motor Learning Processes and Outcomes. Sport, Exercise, and Performance Psychology. Advanced online publication. https://doi.org/10.1037/spy0000260. This paper is not the copy of record and may not exactly replicate the final, authoritative version of the article. The final article will be available, upon publication, via its DOI.

Motor learning is central to sport and exercise contexts and entails learning and refining skills through practice (Fitts \& Posner, 1967). For successful learning, motivation is important-with goals lying at the heart of how individuals initiate, sustain, and evaluate learning activities (Kaplan \& Maehr, 2007). In line with this, the achievement goal approach describes different types of preferences for end states that individuals seek to approach or avoid in achievement contexts, with an individual's (un)desired level of competence typically being at the center of these goals (Elliot \& Fryer, 2008; Hulleman et al., 2010). The pursuit of these different end state preferences (i.e., achievement goals) has been linked to affective, cognitive, and be-

Martin Daumiller, Department of Psychology, University of Augsburg, Germany; Raven Rinas, Department of Psychology, University of Augsburg, Germany; David Jaitner, Department of Sports Science and Movement Pedagogy, Technical University of Braunschweig, Germany.

Correspondence concerning this article should be addressed to Martin Daumiller, Department of Psychology, University of Augsburg, Universitätsstr. 10, 86159 Augsburg, Germany; Martin.Daumiller@phil.uni-augsburg.de. ORCID: 0000-0003-0261-6143. havioral consequences in diverse populations, including students and athletes (see Hulleman et al., 2010; Payne et al., 2007; Senko et al., 2011).

Based on this, the achievement goals that individuals pursue can be expected to matter for motor learning in sport and exercise contexts (Lewthwaite \& Wulf, 2012). The available, albeit sparse literature on this topic primarily focuses on formal learning contexts (e.g., school physical education; see Jaitner et al., 2019), while studies concerning the role of achievement goals for informal motor learning activities (e.g., independently mastering existing skills or learning new movements such as juggling) are rare. Such activities, however, are prevalent and unique in that direct observation, guidance, and support from trained professionals are not readily available, making self-regulated motor learning activities of particular research interest. Thus, gaining more knowledge on this topic is necessary to understand and support learners' self-regulated motor learning endeavors.

Another issue that is still not sufficiently understood in achievement goal research pertains to the temporal variability of achievement goals. While it has been established that achievement goal preferences contain fractions that are stable and fractions that vary over 
time, little is known about these characteristics of goal pursuit in sport and exercise contexts, or about the relevance of change and temporal trends in achievement goal pursuit in general. As learning is not always a linear process, but can involve ups and downs eventuating in skill development, research on this topic is especially important. Specifically, for motor learning processes such as the time and effort invested in learning or the experience of motivational problems, changes in current goals might, for instance, be more relevant than general goal preferences (see Goetz et al., 2016). Moreover, for motor learning outcomes such as performance and continuance intentions, not only the average levels of such goals during learning may matter, but also their temporal trajectories (e.g., an increase in learning goals throughout the learning processes). Addressing such changes and trends in achievement goals will allow us to better understand their relevance for learning processes and outcomes, which is (a) critical for improving knowledge on achievement goal pursuit and its regulation, and (b) fundamental for initiatives directed at supporting (motor) learning processes.

In the current study, we address the aforementioned research gaps by combining the two understudied areas of self-regulated motor learning and temporal achievement goal variability. Specifically, we report on a longitudinal diary study, in which we investigate the temporal variability of achievement goals and their relevance for learning how to juggle.

\section{Relevant Self-regulated Motor Learning Processes and Outcomes}

Motor learning often occurs outside of formal or supervised learning contexts within the scope of self-organized practice and self-regulated learning. In selfregulated learning, learners systematically activate, regulate, and control (meta)cognitions, affects, behaviors, and further resources to achieve personal goals (Zimmerman \& Schunk, 2008). To describe self-regulated learning processes, Zimmerman (2000) developed the cyclical model of self-regulated learning, which is widely used in sport and exercise contexts (Zimmerman, 2013) and continuously combines three phases: forethought (encompassing motivations and task analysis), performance (the execution of the task including self-control and self-observation processes), and self-reflection (assessments and reactions concerning how the task was performed). As in the present study we explicitly focus on the motor learning context, we therefore speak of self-regulated motor learning. SRML typically constitutes an explicit achievement context where individuals learn and their performance matters, particularly in terms of judging their competencies based on self- or other-based standards.

SRML can be powerful for deep learning, performance, and retention (Keetch \& Lee, 2007; Zimmerman, 1996, 1998). However, such research works also show that individuals strongly differ in the extent to which they self-regulate their motor learning processes, which in turn, impacts their learning outcomes. In particular, following Zimmerman (2000), learning time, effort, and motivational problems can be considered central self-control and self-monitoring processes located within the performance phase of SRML. Learning time refers to the time explicitly invested in motor learning practice, effort describes the level of determination put forth during practice, and motivational problems entail difficulties in maintaining training motivation throughout practice. Regarding these learning processes, not only variability between individuals (interindividual differences), but also variability within a given individual over the course of practicing new movements (i.e., intra-individual differences) is likely. Furthermore, individuals also differ in outcomes of their motor learning activities - particularly regarding their performance, that is, how well they do regarding the specific skills they set out to learn (Zimmerman, 2013), and their continuance intentions, that is, their evaluations concerning their decision to continue practicing in the future.

To explain these differences in SRML processes and resulting outcomes, learners' achievement goals can be considered central motivational antecedents within the forethought phase of SRML. Achievement goals encompass the question of why an individual pursues tasks in achievement settings, as well as the standards they use to guide and evaluate their progress (Pintrich, 2000; Zimmerman, 2000). For example, strong aims to increase one's competencies in a SRML skill, such as juggling, can be expected to go along with monitoring cues that indicate progress in learning, as well as the use of learning strategies that focus on progressing toward the goal of mastery and learning. In this respect, achievement goals can be considered highly relevant for SRML processes and outcomes (Pintrich, 2000).

\section{Achievement Goals and their Relevance for SRML Processes and Outcomes}

Original works on achievement goals identified two primary types of goals (see Korn et al., 2019): mastery goals focused on increasing, improving, or developing 
one's competence through the use of self-based standards; and performance goals focused on demonstrating or proving one's competence through the use of normative standards. Based on this, several different achievement goal models have been articulated. In contemporary achievement goal research, there is consensus that at least three different (sub)types of the original mastery and performance goals should be distinguished, namely: learning approach, performance approach, and performance avoidance goals (see Lochbaum et al., 2017; Murayama et al., 2012; Senko et al., 2011; and Daumiller et al., 2019, for a comprehensive overview model). Additionally, work avoidance goals are also frequently considered in achievement goal research (King \& McInerney, 2014) and may be particularly relevant for autonomous learning activities.

Learning approach goals are defined as aims to increase one's competencies, such as learning new skills and increasing knowledge. Several researchers have further differentiated goal pursuit by additionally considering learning avoidance goals (i.e., striving not to do worse than before) and task goals (where success is defined based on task-based instead of self-based standards; e.g., Mascret et al., 2015) as further subtypes of mastery goals. To be conceptually precise and to allow for clear interpretations, we focus solely on learning approach goals in the present work. Among the mastery-based goals, learning approach goals can be considered as highly relevant for motor learning, given their focus on competence growth and self-development. Within sport and exercise contexts, they have been found to be particularly adaptive for motor learning, as illustrated by positive links with positive affect and self-esteem (Ntoumanis \& Biddle, 1999; Adie et al., 2008), enjoyment (Morris \& Kavussanu, 2009), self-determined motivation and competence (Fernández-Rio et al., 2014), effort (Lochbaum et al., 2020), as well as interest and performance (Hulleman et al., 2010; Van Yperen et al., 2014). A focus on such goals has also been associated with increased learning time when practicing a novel motor task (Kavussanu et al., 2009). Given this background, learning approach goals can be expected to be positively related to SRML processes and outcomes.

Performance goals in sport and exercise contexts are typically defined in line with Elliot and McGregor (2001) as strivings to perform better than others (performance approach) or to avoid doing worse than others (performance avoidance). As such, we also define these goals based on such normative comparisons. Overall, meta-analytic evidence suggests that perfor- mance approach goals are linked to positive experiences, effort, and performance within sport and exercise contexts (Lochbaum et al., 2020; Van Yperen et al., 2014). These findings are sensible for highly competitive contexts where excelling past others is the primary objective (e.g., competitions). However, investigations into performance approach goals in sport and exercise contexts also frequently yield inconclusive results, depicting both positive and negative associations with outcomes or no associations at all (e.g., Adie et al., 2008, 2010; Conroy et al., 2006; Cury et al., 2002; Morris \& Kavussanu, 2009). This inconclusive pattern could be a function of normative comparisons not being suitable for supporting sustainable learning processes. However, being oriented at surpassing others in normative comparison, might lead individuals to strongly focus on building up the type of performance relevant for these normative comparisons (as indicated with the clear links to performance in meta-analyses; Lochbaum et al., 2020; Van Yperen et al., 2014). Given this background, we did not formulate directed hypotheses as to how performance approach goals may be related to SRML processes and continuance intentions, but expected a positive link with performance.

In contrast, performance avoidance goals combine an unfavorable avoidance orientation with an achievement standard that can be expected to impair learning processes due to adverse thoughts and focus. Empirically, such goals have consistently been found to be maladaptive for motor learning: Performance avoidance goals have been associated with negative reactions to imperfections (Stoeber et al., 2008), impaired performance outcomes (Hulleman et al., 2010; Van Yperen et al., 2014), amotivation (Lochbaum et al., 2020), concentration disruption, and worry (Morris \& Kavussanu, 2009). Moreover, they have also been negatively linked to positive affect (Adie et al., 2010), intrinsic motivation (Conroy et al., 2006), and incremental beliefs about sport ability and perceptions of physical education competence (Cury et al., 2002). As such, we expected performance avoidance goals to be negatively related to SRML processes and outcomes.

Finally, work avoidance goals describe aims of getting through the day with little effort (King \& McInerney, 2014). In contrast to mastery- and performancebased goals, work avoidance goals have not frequently been included in achievement goal research in sport and exercise contexts. However, given their maladaptive associations with learning processes and outcomes in school and professional training contexts (e.g., learning engagement and achievement; Daumiller et al., 2020; King \& McInerney, 2014; Skaalvik, 1997), they 
can be expected to also be negatively linked to SRML processes and outcomes. Consequently, including both performance avoidance and work avoidance goals and testing their relevance for SRML can also help shed light on detrimental consequences of goal setting processes.

Taken together, learning approach, performance approach, performance avoidance, and work avoidance goals can be considered relevant for SRML. While this is well documented for learning in the academic context, empirical investigations do not often consider motor learning processes and outcomes - which constitute core aspects of sport and exercise contexts. Instead, previous works have typically considered related aspects such as emotions, beliefs, or well-being, that are useful for deriving expectations regarding the functionality of the individual goals for core motor learning processes, such as learning time, effort, and performance. Furthermore, on a more general level, investigations into the relevance of achievement motivations for motor learning predominantly focus on the influence of environmental circumstances and goal structures (Palmer et al., 2017), while personal motivations such as achievement goals are still not thoroughly understood. Therefore, the present research constitutes a double-barreled step forward in motivational research on SRML in narrowly investigating core differences in motor learning as well as gaining a more comprehensive understanding of achievement goals. The latter also refers to important characteristics of these goal pursuit processes such as their temporal variability.

\section{Temporal Variability of Achievement Goals and their Relevance for SRML}

Achievement goal pursuit contains fractions that are rather stable or variable over time (Bürger \& Schmitt, 2017; Fryer \& Elliot, 2007; Praetorius et al., 2014). Pursued achievement goals can be based on the one hand on global traits of the individual, their familiarity with the novel motor task and its format, standards of the surrounding environment, etc. and on the other hand, on current mood, changing circumstances, or experienced emotions when learning.

Empirical investigations exploring the temporal variability of achievement goals mainly exist for the academic context (e.g., Bong, 2005; Fryer \& Elliot, 2007; Senko \& Harackiewicz, 2005; for an overview see Scherrer \& Preckel, 2019), with retest correlations ranging between $r=.40$ and $r=.70$ (see Senko et al., 2011). A similar pattern of temporal variability is ob- served in sport and exercise contexts, where most studies on the stability of achievement goals are situated in physical education classes (e.g., Warburton \& Spray, 2017; Yli-Piipari et al., 2013). The few studies conducted outside the formal educational context investigated athletes' goals across a season and found largely comparable retest-correlations (Sage \& Kavussanu, 2008; Williams, 1998). These studies indicate that goals contain about half stable and half variable fractions over time, with performance and work avoidance goals typically being more stable than learning goals (see also Praetorius et al., 2014). While most studies were conducted across time spans of multiple months, substantial variability can also be expected on a day-today basis. In a first study, Conroy et al. (2003) examined a sample of 356 recreational athletes over 21 days and found similar stability scores to those presented above (see also Janke \& Dickhäuser, 2018, for similar results in academics). Albeit very little being known about the temporal variability of goal pursuit on a dayto-day basis, particularly in sport and exercise contexts, these rather similar findings across different populations, domains, and time-intervals make it probable that similar stability scores should also be found for goal pursuit during SRML. Testing this assumption is required for a thorough understanding of the variability of achievement goals, which in turn is crucial for a theoretical understanding of this approach, practical implications, and a proper assessment of goals (Praetorius et al., 2014).

Building on this temporal variability of achievement goal pursuit during motor learning, two important research directions emerge that have not yet been systematically addressed but can offer important insights into the associations between goals and motor learning (see also Stenling et al., 2017). First, the relationship between achievement goals and other variables, such as learning processes, may differ on an inter- and an intraindividual level (i.e., depending on whether betweenperson or within-person covariation is analyzed). In fact, these two types of relationships are typically statistically independent and can produce opposite relationships (Murayama et al., 2017). However, most of the empirical research on the nomological net of achievement goals has relied on between-person analyses where constructs are assessed with typically one or a few measurement points for each person and interindividual differences are examined. Opposed to this, within-person analyses where individuals are assessed multiple times and relationships between these assessments are computed within individuals are lacking (Murayama et al., 2017; cf. Goetz et al., 2016). While 
the outlined theoretical links between goals and learning processes apply for both levels, they could possibly vary on between-person and within-person levels. For example, between-person differences in performance approach goals may be associated with increased learning effort through a more intensely set-out training regime, while having stronger performance goals on a particular day may be negatively related to a person's deviations from their usual learning effort given an increase in off-task thoughts. Finding such differences can be very helpful for better understanding the shortand long-term functionality of achievement goals for motor learning. Furthermore, even if the associations between achievement goals and learning processes do not systematically vary on both levels, finding effects on the within level are crucial, as they are required to facilitating practical implications directed at supporting adaptive goal pursuit (see Voelkle et al., 2014).

Beyond within-person and between-person differences, a second aspect of the variability in the goals pertains to temporal trends. Specifically, two particular learners may not differ in their mean learning goals over the course of learning a new motor task. However, the first person might increase their learning goals throughout learning, while the second person's learning goals might decrease over time. Such trends could additionally be informative for understanding differences in SRML, e.g., the second learner's continuance intentions might be lower than that of the first learner. To the best of our knowledge, the relevance of such temporal trends for motor learning outcomes have not been systematically examined.

\section{The Present Research}

In the present research, we investigated changes and trends in achievement goal pursuit over time and their relevance for motor learning processes and learning outcomes. We focused on an autonomous phase of learning new movement competencies (juggling) over the course of two weeks and explored an often overlooked aspect of achievement goal pursuit, namely that not only the extent of achievement goal pursuit matters, but also the change in goals.

First, we were interested in the extent of stability and change of achievement goals when learning juggling. Building on our reflections on the temporal stability of achievement goals and previous research findings on different populations and contexts, we hypothesized that learners' achievement goal pursuit contains both substantial temporally stable as well as temporally variable fractions (H1). Specifically, we expected learning approach goals to be more variable than performance approach, performance avoidance, and work avoidance goals.

Based on this, we wanted to investigate how learners' day-to-day deviations in their achievement goal pursuit matter for learning processes (within-person associations) and compare these to the general effects over time (between-person associations). As relevant motor learning processes, we focused on effort, learning time, and the occurrence of motivational problems. Following theoretical and empirical considerations of the role of different achievement goals for learning processes, we hypothesized for both the within-person and the between-person level, that learning approach goals are positively associated with learning time and effort and negatively associated with motivational problems (H2a). We additionally hypothesized that performance avoidance and work avoidance goals are negatively associated with learning time and effort and positively associated with motivational problems $(\mathrm{H} 2 \mathrm{~b}, \mathrm{H} 2 \mathrm{c})$. We did not formulate directed expectations for performance approach goals. Further, we acknowledged that there might be differences between within-person and between-person associations, which we analyzed in an exploratory manner.

Finally, we aimed to examine the effect of the average levels across the different measurement points per person (i.e., the mean levels) and the linear trends over time per person (i.e., the slopes) of achievement goal pursuit on two central learning outcomes: performance and continuance intentions. We hypothesized that the mean level and slope of learning approach goals are positively associated with performance and continuance intentions (H3a), that the mean level and slope of performance approach goals are positively associated with performance $(\mathrm{H} 3 \mathrm{~b})$, and that the mean levels and slopes of performance avoidance goals and work avoidance goals are negatively associated with performance and continuance intentions $(\mathrm{H} 3 \mathrm{c}, \mathrm{H} 3 \mathrm{~d})$.

\section{Method}

To answer our research questions, we gave students without juggling experience the task of learning how to juggle. After an introduction to basic movements and learning strategies, students had a period of 16 days to learn basic skills autonomously. At the end of each day, they filled out an online learning diary regarding their current goals and their learning processes (time, effort, motivational problems). After the last day, we administered a post-test measuring their learning outcomes (performance, continuance intentions). 


\section{Sample}

Participants were recruited from a German university and received study credits for participation. Based on power analyses, we ex ante decided to recruit a total of 98 students that were unfamiliar with juggling. As five students did not show up for the study, our final sample consisted of 93 students. The students were all teacher trainees in their first year of studies, none of them had PE as a teaching subject, and none of them had practiced juggling before. Their mean age was 20.6 $(S D=2.7, \operatorname{Min}=18, \operatorname{Max}=36)$ years and, typical for their study program, most were female $(75 \%)$. On average, they completed 10.9 of the 16 diary assessments $(\mathrm{SD}=2.9, \mathrm{Min}=6, \mathrm{Max}=16)$, resulting in a total of 1,017 daily assessments.

\section{Measures $^{1}$}

Daily assessments. To keep the daily assessments as concise as possible (which was required for high participation rates and acceptance by the participants), we used single items. The reliability and validity of such an approach has been supported for measuring motivations and experiences (see e.g., Goetz et al., 2007, Gogol et al., 2014, Van Hoff et al., 2007, Wright \& Zimmermann, 2019). Taken together, these studies document that single-items work especially well and adequately when the constructs to be measured are concrete, highly schematized for most individuals, and reflect subjective experiences (see Robins et al., 2001). We consider this assumption to be fulfilled for learning time, effort, and motivational problems, which we assessed either with clear measures that were already used as single items in past research, or measures that were easily answerable. In line with Goetz et al. (2016), the same can be expected for achievement goals. As the goals are the key construct of the present work, we additionally followed up on the adequacy of using single items to assess them by including the full scale at the first measurement point.

Achievement goals. We used a juggling-specific adaptation of the achievement goal scale by Daumiller et al. (2021). The single items were selected based on prior research on a long form of this scale to contentvalidly reflect the type of goal in question while addi- tionally taking their item-total-correlations into consideration. Participants were asked to focus their answers on today's learning session. Subsequently, they were asked about the extent of their learning goals ("... it is my goal to continually improve myself"), (normative) performance approach goals ("... it is my goal to outperform the others"), (normative) performance avoidance goals ("... it is my goal to not perform worse than the others"), and work avoidance goals "... it is my goal to have the least amount of work as possible"). All items were to be answered on a Likert-type scale ranging from 1 (do not agree at all) to 8 (agree completely). To determine how well these single items reflected the original scale, we followed the testing procedure from Gogol et al. (2014) and calculated correlations between the single items and the total scale at the first measurement point. Very high correlations $(r=.88-.95)$ indicated that the single items were very similar to the overall scale. We then used the correction of attenuation formula (Nunnally \& Bernstein, 1994) that is widely used to assess the reliability of single-item measures (e.g., Christophersen \& Konradt 2011; Fülöp et al., 2020; Postmes et al. 2013). This yielded very high reliability scores for the single items (.87-.93).

Learning time. To assess participants' learning time, we asked them to write down the time in minutes that they spent practicing juggling on a given day.

Effort. To assess invested effort in juggling practice on a given day, we used a single item adapted from Rotgans and Schmidt (2011) that read "I put in a lot of effort into today's juggling practice" and was to be answered on a Likert-type scale ranging from 1 (do not agree at all) to 8 (agree completely).

Motivational problems. Regarding the occurrence of motivational problems, we used a single item ("...I had difficulties maintaining my training motivation") based on Engelschalk et al. (2016) that was to be answered on a Likert-type scale ranging from 1 (do not agree at all) to 8 (agree completely).

\section{Post-test measures.}

Performance. To measure juggling performance in the post-test, the students had to demonstrate multiple basic juggling tasks and tricks that they had learned. Their performance was graded from 1 to 6 where 1 represented a very good performance as assessed by two trained raters and a set of grading criteria for the six marks $(\kappa=.81)$. In cases of disagreement, the ratings

\footnotetext{
${ }^{1}$ Beyond the herein reported measures, we also examined further achievement goals, namely task approach, task avoidance, learning avoidance, appearance approach, appearance avoidance, and relational goals (see Daumiller et al., 2019). We decided ex ante that these were not relevant for the present research questions, which is why we do not report on their results in this manuscript. Further, we also assessed personality traits for exploratory reasons.
} 
were averaged. To facilitate better interpretability of our findings, we reversed the scores (high values indicating good performance and low values indicating bad performance).

Continuance intentions. To assess participants' continuance intentions, we used an adaption of a scale based on Daumiller et al. (2020) with five items (e.g., "For the upcoming weeks, I have decided to continue practicing juggling.", $\alpha=.88$ ) that was to be answered on a Likert-type scale ranging from 1 (do not agree at all) to 5 (agree completely).

\section{Analyses and Missing Values}

To examine the extent of stability and change in goal pursuit, we first calculated intra-class correlations (ICC1) which are defined as the proportion of betweengroup variance per total variance. Estimates for both variance components and their standard errors were calculated using the MIXED procedure in SPSS (Donner, 1986). We calculated the means of the daily assessments by averaging the respective measure across the different measurement points per person. To determine the temporal trends, we regressed the daily assessments on the time variable (i.e., days). While we were primarily interested in the linear trends of achievement goals, this procedure allowed us to additionally test whether quadratic or cubic trends could also be made out (which was not the case).

Next, we conducted two-level modeling in Mplus 8.1 (Muthén \& Muthén, 2017) using MLR as an estimator. We modeled all variables on the within- and between-person level and regressed learning time, learning effort, and motivational problems on the achievement goals on both levels. Achievement goals were grand-mean centered. ${ }^{2}$ We allowed for correlations between the goals as well as correlations between the outcome variables. Finally, we modeled the means and slopes of the achievement goals across the learning period. In two sets of multiple regression models (for the two learning outcomes as dependent variables), we examined (1) the effect of the means of the goals, (2) the effect of the slopes, and (3) their joint effects. The models were fully saturated and therefore yielded a perfect fit to the data. We considered a $p$ value threshold of .05 to determine statistical significance.

Two participants did not provide answers in the post-questionnaire. Consequently, they were excluded from the last analysis. For the learning diaries, there were some missing measurement points $(M=5.09, S D$ $=2.89$, Min $=0, \operatorname{Max}=10$ out of the 16 diary assessments missing). We ex ante decided to keep participants up to a threshold of 10 missing measurement points, as this amount of missingness should not substantially affect the respective analyses given their nature (in particular, intercepts and slopes can be calculated on the available diary entries). Therefore, no participants were excluded due to too many missing diary entries. We followed up on the assumption of this not affecting our results by testing whether the amount of missing diary entries was related to the slope and intercept estimates of the daily assessments (for which we found no significant associations), and by including the amount of missing measurement points as a control variable in the main analyses (which did not change the results either). This evidence speaks to our results not being distorted due to missing data. On the variable level, there was only a single item in the daily assessments that was once left unanswered. This was handled using the full-information maximum likelihood estimation (FIML) procedure in Mplus.

\section{Results}

\section{Stability and Change of Achievement Goal Pursuit}

Descriptive statistics for all measures can be found in Table 1. These results document substantial differences between the participants in their goals, learning processes, and learning outcomes. An investigation of the intra-class correlations indicated that slightly more of the variance in achievement goal pursuit could be attributed to stable between-person differences. Descriptively, learning goals $(\mathrm{ICC} 1=.56,90 \%$ confidence interval: $[.47 ; .64])$ depicted more variability over time than performance approach $(\mathrm{ICC} 1=.70[.62 ; .76])$, performance avoidance $(\mathrm{ICC} 1=.71[.62 ; .77])$, and work avoidance (ICC1 = .65 [.56; .71]) goals, however, an investigation of the confidence intervals revealed that

\footnotetext{
${ }^{2}$ Besides centering, another important choice in multilevel longitudinal modelling pertains to detrending (Wang \& Maxwell, 2015). As we considered trends in goals and learning processes to be attributable to our study design (in which we asked participants to learn how to juggle), we did not detrend variables in this analysis. However, considering the effects that detrending choices could possibly have on the results, we reran the analyses again with detrending the predictors and outcomes by adding time as a covariate on the within-level. With the exception of the small negative association between work avoidance goals and learning time that was no longer statistically significant, the results did not change. As such, our findings can be considered as largely robust with regard to detrending choices.
} 
Table 1

Descriptive Statistics and Associations Between Means and Slopes of Achievement Goals and Learning Processes with Learning Outcomes

\begin{tabular}{|c|c|c|c|c|c|c|c|c|c|c|c|c|c|c|c|c|c|c|c|}
\hline & \multicolumn{5}{|c|}{ Descriptives for the means } & \multicolumn{5}{|c|}{ Descriptives for the slopes } & \multicolumn{9}{|c|}{ Bivariate correlations } \\
\hline & $M$ & $S D$ & Min & Max & Skew & $M$ & $S D$ & Min & Max & Skew & 1 & 2 & 3 & 4 & 5 & 6 & 7 & 8 & 9 \\
\hline \multicolumn{20}{|l|}{ Achievement goals } \\
\hline 1 Learning approach & 5.68 & 1.37 & 2.0 & 8.0 & -0.40 & $-.27^{*}$ & $.45^{*}$ & -.93 & .75 & 0.63 & & .11 & .23 & -.04 & .34 & .47 & -.18 & .42 & .25 \\
\hline 2 Performance approach & 2.87 & 1.53 & 1.0 & 8.0 & 0.80 & $-.12^{*}$ & $.46^{*}$ & -.79 & .90 & 0.77 & .19 & & .74 & -.06 & .12 & .11 & -.07 & -.04 & -.17 \\
\hline 3 Performance avoidance & 3.58 & 1.71 & 1.0 & 8.0 & 0.27 & -.03 & $.47^{*}$ & -.87 & .93 & 0.05 & .13 & .82 & & -.04 & .19 & .12 & -.07 & .09 & -.17 \\
\hline 4 Work avoidance & 4.49 & 1.55 & 1.0 & 7.8 & -0.07 & $.20^{*}$ & $.43^{*}$ & -.91 & .88 & -0.23 & -.39 & -.12 & .08 & & -.06 & -.19 & .29 & -.24 & -.01 \\
\hline \multicolumn{20}{|l|}{ Learning processes } \\
\hline 5 Learning time (minutes) & 14.23 & 8.42 & 3.5 & 50.5 & 2.15 & $-.31^{*}$ & $.34^{*}$ & -.92 & .91 & 1.11 & .35 & .37 & .22 & -.44 & & .52 & -.55 & .07 & -.02 \\
\hline 6 Effort & 4.10 & 1.20 & 1.8 & 7.2 & 0.30 & $-.14^{*}$ & $.38^{*}$ & -.87 & .63 & 0.13 & .50 & .24 & .09 & -.32 & .55 & & -.39 & .20 & .07 \\
\hline 7 Motivational problems & 4.73 & 1.37 & 1.0 & 7.8 & -0.30 & $.22^{\star}$ & $.34^{*}$ & -.50 & .87 & -0.18 & -.34 & -.18 & -.05 & .73 & -.53 & -.58 & & .02 & .05 \\
\hline \multicolumn{20}{|l|}{ Learning outcomes (post-test) } \\
\hline 8 Performance & 2.82 & 1.12 & 1.5 & 6.0 & 0.24 & & & & & & .35 & -.18 & -.21 & -.41 & .28 & .33 & -.50 & & \\
\hline 9 Continuance intentions & 2.53 & 1.10 & 1.0 & 5.0 & 0.30 & & & & & & .26 & .18 & .11 & -.35 & .29 & .30 & -.33 & -.22 & \\
\hline
\end{tabular}

Note. $N=93$. Lower triangular matrix shows correlations between means of goals, learning processes, and learning outcomes with means of goals, learning processes, and learning outcomes; upper triangular matrix shows correlations between slopes of goals and learning processes with slopes of goals and learning processes as well as means of learning outcomes. All statistically significant correlations at $p<.05$ are boldfaced.

* indicates that these parameters were statistically significantly different from zero $(p<.05)$.

these differences were not statistically significant. Opposed to that, learning time, effort, and motivational problems during the learning phase exhibited much more day-to-day fluctuations, ICC1(learning time) = $.14[.08 ; .19]$, ICC1(effort) $=.22[.14 ; .29]$ ICC1(motivational problems $)=.27[.19 ; .34]$.

\section{Within-person and Between-person Associations Between Achievement Goals and Learning Processes}

We analyzed the within-person and between-person associations between achievement goals and the learning processes of learning time, effort, and motivational problems by estimating a two-level model (Figure 1). The results showed that learning approach goals were statistically significantly and positively associated with all three learning processes on the within-person level; on the between level, this link was found for learning time and effort but not for motivational problems. This means that a learner's deviation from their general learning goal pursuit mattered substantially for day-today differences in motivational problems, but that these associations were not evident regarding the fractions of both constructs that were stable across time. For performance approach goals, we found a negative within-person association with motivational problems experienced by the students, as well as a statistically significant positive link with learning times and effort on the between-level. Thus, person-stable fractions of performance approach goals were positively linked to stable differences in learning times and effort invested during the learning phase, but such a positive link was not found regarding day-to-day fluctuations in these measures. In contrast, we did not find significant associations between performance avoidance goals and the learning processes. Finally, the strength of work avoidance goals was negatively linked to learning time and positively linked to motivational problems on both the within-person and the between-person level. On the former level, we also found a negative association regarding effort. Taken together, the achievement goals explained nearly half of the variance on the betweenperson level and $8-17 \%$ on the within-person level. Considering the ICCs of these learning processes (that indicated much more variance on the within than on the between level), overall $14 \%$ of variance in learning time, $22 \%$ of variance in effort, and $30 \%$ of variance in motivational problems was explained, with the withinperson fractions of achievement goal pursuit having similar exploratory power as their between part.

\section{Effects of Means and Slopes of Achievement Goals on Learning Outcomes}

An investigation into the overarching temporal trends (i.e., the slopes), indicated a linear decrease in learning approach and performance approach goals and an increase of work avoidance goals paired with decreasing learning time and effort and increasing motivational problems over the 16 days (see Table 1). Despite these average developments over time, we found 


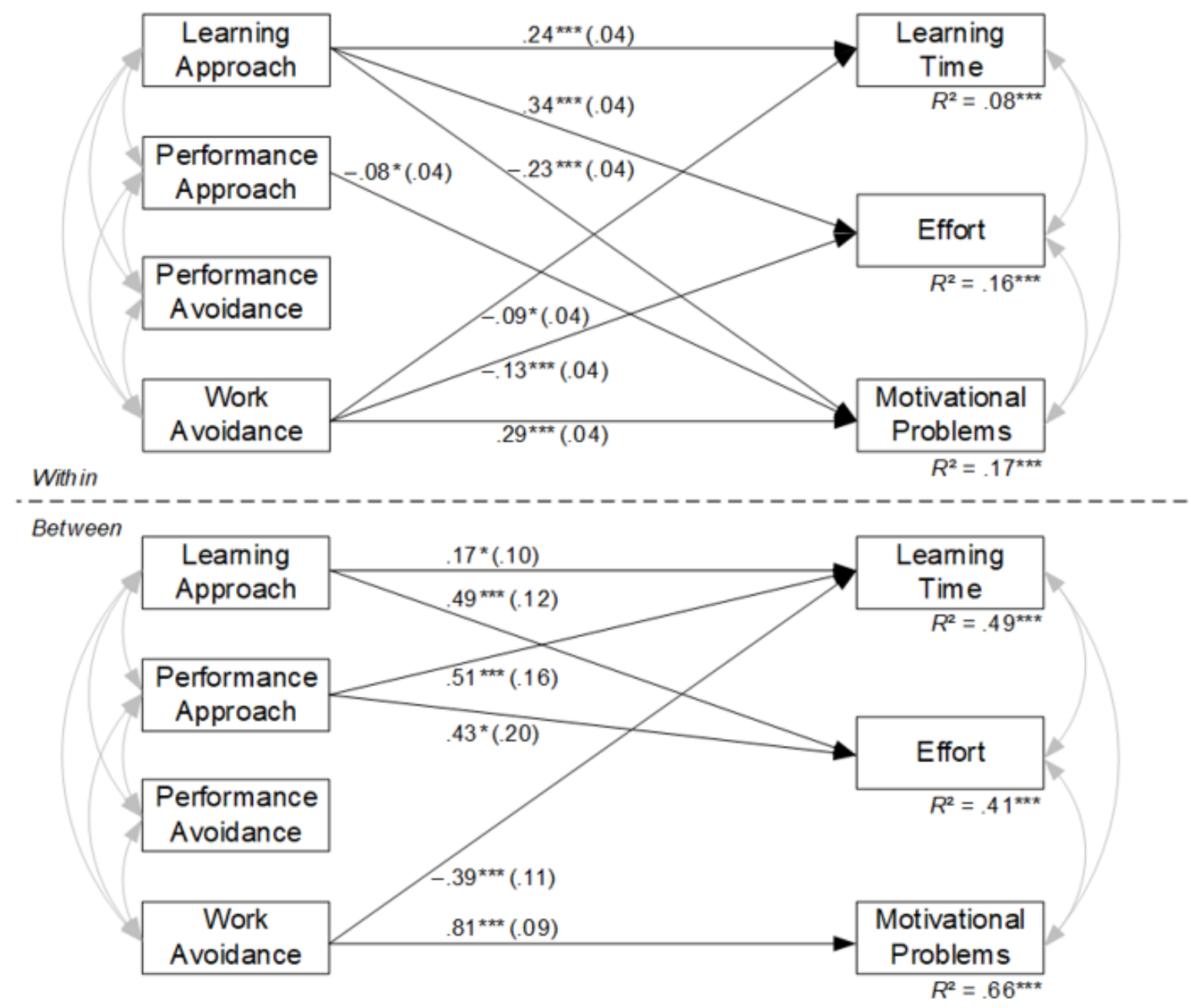

Figure 1. Results of two-level modelling the associations between achievement goals and learning time, effort, and motivational problems during self-regulated motor learning.

( $N=1,017$ single measures nested in $N=92$ students. Correlations between achievement goals and between the three dependent variables were modeled but are not reported for clarity. As the model was fully saturated it exhibited a perfect fit to the data. Reported are standardized coefficients. *: $p<.05,{ }^{* *}: p<.01, * * *: p<.001$ )

meaningful differences between individuals in these temporal trends (reflected in the statistically significant standard deviations of the slopes and their large range).

Regressing participants' performance at the end of the study on the means and slopes of their achievement goals (see Table 2) indicated that the mean levels of learning approach goals during the learning phase were positively associated with subsequent performance, while the opposite pattern was found for work avoidance goals. Beyond these mean level effects, also their slopes mattered: Those who managed to maintain their learning goals or even increase them had higher perfor- mance opposed to those with more strongly deteriorating learning approach goals, while again, a negative effect was found for the slope of work avoidance goals. Together, means and slopes of the goals explained nearly half of the variance in the participants' subsequent performance. For continuance intentions, we found that the mean levels of work avoidance goals were negative predictors and that the slope of learning approach goals was a positive predictor of subsequent motivation to continue juggling, however, the other effects were not statistically significant. ${ }^{3}$

\footnotetext{
${ }^{3}$ We also estimated the models using only the slopes or only the means as predictors. This did not yield different results, which we interpret as indication for the robustness of our findings.
} 
Table 2

Regression Models on the Effects of Means and Slopes of Achievement Goals During Learning on Learning Outcomes

\begin{tabular}{|c|c|c|c|c|}
\hline & \multicolumn{2}{|c|}{$\begin{array}{c}\text { Model 1: } \\
\text { Performance }\end{array}$} & \multicolumn{2}{|c|}{$\begin{array}{l}\text { Model 2: } \\
\text { Continuance } \\
\text { intentions }\end{array}$} \\
\hline & $\beta$ & $p$ & $\beta$ & $p$ \\
\hline \multicolumn{5}{|l|}{ Means } \\
\hline Learning approach & .18 & .043 & .12 & .171 \\
\hline Performance approach & -.31 & .093 & .10 & .633 \\
\hline Performance avoidance & .02 & .448 & .06 & .768 \\
\hline Work avoidance & -.33 & .001 & -.27 & .018 \\
\hline \multicolumn{5}{|l|}{ Slopes } \\
\hline Learning approach & .35 & $<.001$ & .25 & .014 \\
\hline Performance approach & -.05 & .358 & -.08 & .621 \\
\hline Performance avoidance & .05 & .359 & -.16 & .356 \\
\hline Work avoidance & -.19 & .025 & .07 & .254 \\
\hline$R^{2}$ & .45 & & .25 & \\
\hline
\end{tabular}

Note. $N=93$.

\section{Discussion}

We investigated the role of achievement goals for SRML by combining two previously overlooked aspects in achievement goal research: SRML as a central achievement domain in sport and exercise contexts, and the point that not only the extent of achievement goal pursuit matters, but also the change in goals. To this end, we conducted a longitudinal diary study with students who autonomously learned juggling basics. Strengths include the large sample size on the level of the individual diary entries, the inclusion of objective learning outcomes, and the systematic consideration of within- and between-person effects as well as mean levels and trajectories of achievement goals. Our findings document that achievement goal pursuit during motor learning contains both temporally stable as well as variable fractions, with especially learning approach and work avoidance goals mattering for motor learning. Aside from the relevance of stable components of goal pursuit, we found day-to-day fluctuations in goals equally important for learning processes; while for performance and continuance intentions, both average levels and temporal trajectories of goals were predictive.

Concerning the extent of stability and change of achievement goals throughout learning how to juggle (H1), consistent with our expectations and research in the sports and exercise context (e.g., Barkoukis et al., 2010; Conroy et al., 2003; Sage \& Kavussanu, 2008;
Williams, 1998), students' goals contained both stable and variable fractions over time, with slightly more stable fractions. This supports the notion that daily goals are partly due to overarching factors such as the stable evaluation context or students' achievement motives for juggling, and partly due to temporally variable aspects such as students' daily mood or successes and failures while juggling. Albeit not statistically significant, the descriptive differences between the goals were similar to those commonly found in the academic context (e.g., Praetorius et al., 2014; see Bürger \& Schmitt, 2017). Theoretically, it makes sense that learning approach goals may vary more than performance approach, performance avoidance, or work avoidance goals as a function of different learning contents (that vary in their appeal, perceived relevance, and interestingness). However, these differences in learning content over time are likely larger in schools (e.g., the content of PE classes often varies substantially over the course of multiple lessons) than in the more narrowly defined scenario of learning juggling. This might impact how strongly temporal stability varies between the different types of goals. Future research would profit from more strongly considering such contextual conditions to better understand differences in temporal stability of achievement goal pursuit.

Our second aim was to understand how students' daily achievement goal pursuit mattered for their learning processes. Concerning the specific associations be- 
tween goals and learning time, learning effort, and motivational problems, our results largely support previous findings and reasoning regarding the general nature of each goal for learning. Specifically, in line with our predictions (H2a) and prior results in sports and exercise contexts (e.g., Cury et al., 1997; Kavussanu et al., 2009; Shen et al., 2007), learning goals were highly functional for all three learning processes. This strongly supports the relevance of such motivations for successful learning. Moreover, similar to Kavussanu et al. (2009), performance approach goals were rather adaptive, having negative associations with motivational problems and positive associations with learning time and effort. Contrary to expectations, we did not find support for the predicted maladaptive effects of performance avoidance goals for learning (H2b), however, our results support our hypothesis on work avoidance goals in that they were linked to all learning processes in the assumed direction (H2c). This corresponds to the generally maladaptive nature of work avoidance goals for learning contexts (e.g., Daumiller et al., 2019; Harackiewicz et al., 1997) and will be discussed together with the surprising results for performance avoidance goals further on.

A main innovation of our analytic strategy involved the consideration of within- and between-person effects, which are often neglected in goal research $(\mathrm{Mu}-$ rayama et al., 2017). Our findings lend support to achievement goals generally being similarly related to learning processes on both levels (see Goetz et al., 2016), however, there were also specific effects that warrant attention. Notably, performance approach goals were associated with motivational problems only on the within-person level and related to learning time and effort only on the between-person level. This means that the general levels of performance approach goal pursuit mattered for learning time and effort; but day-to-day deviations from these general levels did not covary with deviations in learning time and effort. This could imply that performance goals are primarily relevant within the scope of overall planning phases of selfregulated learning (see Zimmerman \& Schunk, 2008), in that individuals who tend to strongly value outperforming others might set more intense and ambitious training regimes in which they generally exert more learning time and effort. Day-to-day deviations from these general performance goal levels might not substantially matter for whether individuals use more or less learning time and effort a given day than usual (here, instead, current learning and work avoidance goals may be decisive, as also seen in our findings). However, the within-person changes in performance goals may still contribute to how this person experiences and interprets their learning processes in that a higher experience of motivational problems becomes more likely when strongly focused on outperforming others on a given day (due to the adverse focus of thoughts and cognitions).

This can therefore be considered as preliminary evidence that performance goals might be differentially related to self-regulated learning processes on the within- and the between-person level. Within- and between-person differences in the effects of performance goals on learning processes could also explain why inconsistent findings are often reported for performance goals and learning processes (e.g., Adie et al., 2008; Adie et al., 2010; Conroy et al., 2006; Cury et al., 2002; Morris \& Kavussanu, 2009). Future research should follow up on within-person and between-person effects of performance approach goals to better understand the nature of goal pursuit and how goals matter for learning processes. Moreover, our findings attest that both between- and within-person differences in goal pursuit should be considered to comprehensively understand differences in learning processes.

Furthermore, we also examined the development of goals over time. Over the 16 days of juggling practice, we observed a qualitative deterioration of goal pursuit (reduction of learning and performance approach goals, increase in work avoidance goals) which is consistent with prior research on achievement goal development in sports and exercise contexts (e.g., Barkoukis et al., 2010; Warburton \& Spray, 2017) and in education in general (Scherrer \& Preckel, 2019). Situating the present research in these prior works, it needs to be considered that the temporal trends that we found were rather weak, however, this was to be expected given that our time frame was only about two weeks. Our findings extend prior research through documenting that such temporal trends prevail within a relatively short time span of a non-autonomously chosen learning task. Knowledge about such trends matters for research initiatives aimed at mitigating maladaptive and supporting adaptive goal pursuit over time in SRML. Specifically, learners may benefit from regularly monitoring their goals across learning periods and knowing about resources tailored to dealing with specific motivational problems (e.g., those who recognize themselves to have increasing work avoidance goals might remind themselves of the value of their motor learning pursuit and the benefits it can provide). The rationale for such tailored approaches is also reflected in the substantial in- 
terindividual variation found in the extent of these temporal trajectories, which also constitutes the premise of our final research aim.

In our final set of hypotheses, we examined the relevance of mean levels and temporal trends of achievement goals on performance and continuance intentions as two central learning outcomes. In line with expectations (H3a) and the general adaptive nature of learning approach goals for success in sport and exercise contexts (e.g., Lochbaum \& Gottardy, 2015) as well as for motor learning specifically (Kavussanu et al., 2009), the average levels of learning approach goals during the learning period were predictive of performance in the post-test. Furthermore, as predicted (H3d) and in accordance with findings indicating that work avoidance goals are detrimental for learning across multiple domains (Daumiller et al., 2020; Harackiewicz et al., 1997; King \& McInerney, 2014), we found the average level of work avoidance goals during learning to negatively predict subsequent performance and continuance intentions. Extending prior research, we did not only consider average levels of goals but also their trajectories over the course of the 16 days. The results for performance strongly supported our hypotheses that both average levels as well as temporal trajectories are relevant. Students who had high levels of learning goals, and those who managed to increase their learning goals over time (or at least had no strong deterioration of these goals) scored best in the performance test, while the opposite was observed for work avoidance goals. For continuance intentions, we found a more nuanced pattern of results. While we did not find support for average levels of learning goal pursuit mattering for this outcome, the temporal trajectories of pursuing such goals were very relevant. Conversely, only the average levels of work avoidance goals over time were associated with continuance intentions, but not their temporal trajectories. This might mean that increases or decreases of learning goals might reflect whether someone is building up or losing interest in the learning content (that might drive their subsequent continuance intentions), while changes in work avoidance goals might be largely attributable to other factors, such as temporal constraints or difficulty of the learning topic, that might not matter much for their continuance intentions.

Although these findings provide support that both average levels as well as temporal trends of goal pursuit are relevant for learning outcomes, the interpretations that can be drawn from the effects of the temporal trends are limited as the two outcomes were only assessed in the post-test. Reciprocal relationships may exist that were unobservable in the current study. Specifically, students who did not learn much during juggling from one day to the next, perhaps due to a lack of suitable learning strategies or materials, might not have strongly improved their performance and, as a consequence of low learning progress and setbacks, may have reduced their learning goals and increased their work avoidance goals. As such, the association between the trajectories of these goals and performance might, at least in part, also be explained by the development of the students' performance and their learning progress over time. A similar argument can be made for continuance intentions. While the present research clearly speaks to the relevance of considering goal trajectories and sets the ground for investigations into their effects, future research should also include the temporal processes of learning outcomes to more clearly understand how goals are associated with them.

Finally, in contrast to hypotheses $\mathrm{H} 3 \mathrm{~b}$ and $\mathrm{H} 3 \mathrm{c}$, we did not find support for the relevance of performance approach or avoidance goals for learning outcomes. We also did not find support for performance avoidance goals being linked to learning processes (see H2b). Not finding positive links between performance approach goals and performance might contrast the meta-analytic evidence of this type of goal for performance attainment in sport and exercise contexts (Lochbaum et al., 2020; Van Yperen et al., 2014). However, it is worth noting that linkages between this goal and performance are often not very strong, particularly in the academic context where they are also tied to substantial heterogeneity (Huang, 2012). As such, this might reflect that in a motor learning task, performance approach goals may matter less for performance than in a very strong performance task (such as competitions). The absent effects of performance avoidance goals are particularly surprising, given that their maladaptive effects are consistently documented in the literature (e.g., Hulleman et al., 2010; Van Yperen et al., 2014). To explain these findings, it needs to be considered that the juggling situation in the present study may not have been very strongly tied to normative comparisons. Specifically, the learners were not in direct comparison to each other during practice as they practiced independently, and the performance test might not have inducted very strong normative concerns. The reduced salience of normative comparisons could have mitigated the effects of performance goals. This is partly attributable to study design and partly to the nature of SRML (which can be expected to typically have a lower salience of normative comparison than teacher or instructor focused lessons within formal education). Furthermore, the high levels 
of autonomy regarding planning and conducting learning activities within SRML might be another explaining factor regarding performance avoidance goals having weaker effects than in more formalized achievement context - opposed to work avoidance goals. Specifically, given high autonomy for the learning activities, work avoidance goals may inhibit individuals from learning in an engaged way in the first place, while performance avoidance goals may still drive students to engage in learning (but not necessarily to use particularly advantageous learning strategies). This also speaks to the relevance of considering work avoidance goals and not only performance avoidance goals to better understand the adverse effects that goal pursuit can have (King \& McInerney, 2014).

Taken together, our findings make four central contributions to the literature regarding temporal stability of achievement goal pursuit, within-person and between-person effects, consideration of temporal trends, and inclusion of work avoidance goals. Beyond the issues already discussed, two further limitations need to be considered when interpreting the present findings. First, participants' achievement goals and learning processes were assessed at the end of each day, which may have impacted the effects found on the within and between levels (due to the retrospective assessment of goals). Second, we did not observe actual SRML of the participants, but relied on their self-reports. While effort and occurrence of motivational problems can likely be assessed very well with self-reports, future research would benefit from including more objective aspects of the learning process such as the actual time invested in learning. Despite these limitations, our results provide first steps for practical implications. To support successful motor learning, not only the average motivations of learners should be considered, but also their development over time. Thus, monitoring current goals and their development, for example, through mindful introspection or the use of learning diaries, may act as a preventative measure to detect deteriorations of motivations that can prompt timely interventions. Furthermore, aside from seeking to enhance learning goal pursuit, learners should actively consider and counteract work avoidance goals and the detrimental effects that they often precede (e.g., by relocating resources or reprioritizing tasks).

In conclusion, our research indicates that achievement goal pursuit during motor learning has temporally stable and variable components that are both important for SRML. For a comprehensive understanding, not only between-person differences in goal pursuit, but also changes within individuals and temporal trends of goal pursuit, should be considered.

\section{References}

Adie, J. W., Duda, J. L., \& Ntoumanis, N. (2008). Achievement goals, competition appraisals, and the psychological and emotional welfare of sport participants. Journal of Sport and Exercise Psychology, 30, 302-322. https://doi.org/10.1123/jsep.30.3.302

Adie, J. W., Duda, J. L., \& Ntoumanis, N. (2010) Achievement goals, competition appraisals, and the well- and ill-being of elite youth soccer players over two competitive seasons. Journal of Sport and Exercise Psychology, 32, 555-579. https://doi.org/d4j9

Barkoukis, V., Ntoumanis, N., \& Thøgersen-Ntoumani, C. (2010). Developmental changes in achievement motivation and affect in physical education. Psychology of Sport and Exercise, 11, 83-90. https://doi.org/10.1016/j.psychsport.2009.04.008

Bong, M. (2005). Within-grade changes in Korean girls' motivation and perceptions of the learning environment across domains and achievement levels. Journal of Educational Psychology, 97, 656-672. https://doi.org/10.1037/0022-0663.97.4.656

Bürger, K., \& Schmitt, M. (2017). Students' multiple state goals as a function of appraisals, trait goals, and their interactions. Contemporary Educational Psychology, 51, 464-481.

https://doi.org/10.1016/j.cedpsych.2017.09.006

Christophersen, T., \& Konradt, U. (2011). Reliability, validity, and sensitivity of a single-item measure of online store usability. International Journal of Human-Computer Studies, 69, 269-280. https://doi.org/10.1016/j.ijhcs.2010.10.005

Conroy, D. E., Elliot, A., \& Hofer, S. M. (2003). A 2 x 2 achievement goals questionnaire for sport. Journal of Sport \& Exercise Psychology, 25, 456-476. https://doi.org/10/gf8rqc

Conroy, D. E., Kaye, M. P., \& Coatsworth, J. D. (2006). Coaching climates and the destructive effects of mastery-avoidance achievement goals on situational motivation. Journal of Sport \& Exercise Psychology, 28, 6992. https://doi.org/10.1123/jsep.28.1.69

Cury, F., Biddle, S., Sarrazin, P., \& Famose, J. P. (1997). Achievement goals and perceived ability predict investment in learning a sport task. British Journal of Educational Psychology, 67, 293-309. https://doi.org/10.1111/j.2044-8279.1997.tb01245.x

Cury, F., Elliot, A., Sarrazin, P., Da Fonseca, D., \& Rufo, M. (2002). The trichotomous achievement goal model and intrinsic motivation. Journal of Experimental Social Psychology, 38, 473-481. https://doi.org/10.1016/S0022-1031(02)00017-3

Daumiller, M., Dickhäuser, O., \& Dresel, M. (2019). University instructors' achievement goals for teaching. Journal of Educational Psychology, 111, 131-148. 
Daumiller, M., Rinas, R., \& Breithecker, J. (2021). Elite athletes' achievement goals, burnout levels, psychosomatic stress symptoms, and coping strategies. International Journal of Sport and Exercise Psychology. Advanced online publication. https://doi.org/10.1080/1612197X.2021.18773267

Daumiller, M., Rinas, R., Olden, D., \& Dresel, M. (2020). Academics' motivations in professional training courses. International Journal of Academic Development. https://doi.org/10.1080/1360144X.2020.1768396

Donner, A. (1986). A review of inference procedures for the intraclass correlation coefficient in the one-way random effects model. International Statistical Review, 54, 67-82. https://doi.org/10.2307/1403259

Elliot, A. J., \& Fryer, J. (2008). The goal construct in psychology. In J. Shah, \& W. Gardner (Eds.), Handbook of motivation science (pp. 235-250). Guilford.

Elliot, A. J., \& McGregor, H. A. (2001). A $2 \times 2$ achievement goal framework. Journal of Personality and Social Psychology, 80, 501-519. https://doi.org/g9d

Engelschalk, T., Steuer, G., \& Dresel, M. (2016). Effectiveness of motivational regulation. Learning and Individual Differences, 52, 72-78. https://doi.org/f9h36b

Fernández-Rio, J., Cecchini Estrada, J. A., MendezGimenez, A., Fernández-Garcia, B., \& Saavedra, P. (2014). $2 \times 2$ dominant achievement goal profiles in high-level swimmers. European Journal of Sport Science, 14, 265-272. https://doi.org/d4kc

Fitts, P., \& Posner, M. (1967). Human performance. Brooks/Cole.

Fryer, J. W., \& Elliot, A. J. (2007). Stability and change in achievement goals. Journal of Educational Psychology, 99, 700-714. https://doi.org/10.1037/00220663.99.4.700

Fülöp, F., Bőthe, B., Gál, É., Cachia, J., Demetrovics, Z., \& Orosz, G. (2020). A two-study validation of a singleitem measure of relationship satisfaction. Current Psychology. 1-13.

Goetz, T., Sticca, F., Pekrun, R., Murayama, K., \& Elliot, A. J. (2016). Intraindividual relations between achievement goals and discrete achievement emotions. Learning and Instruction. 41, 115-125. https://doi.org/10.1016/j.learninstruc.2015.10.007

Goetz, T., Preckel, F., Pekrun, R., \& Hall, N. (2007). Emotional experiences during test taking. Learning and Individual Differences, 17, 3-16. https://doi.org/d5tptz

Gogol, K., Brunner, M., Goetz, T., Martin, R., Ugen, S., Keller, U., Fischbach, A., \& Preckel, F. (2014). "My questionnaire is too long!". Contemporary Educational Psychology, 39, 188-205. https://doi.org/10.1016/j.cedpsych.2014.04.002

Harackiewicz, J. M., Barron, K. E., Carter, S. M., Lehto, A. T., \& Elliot, A. J. (1997). Predictors and consequences of achievement goals in the college classroom. Journal of Personality and Social Psychology, 73, 1284-1295. https://doi.org/cscjwm
Huang, C. (2012). Discriminant and criterion-related validity of achievement goals in predicting academic achievement. Journal of Educational Psychology, 104, 48-73. https://doi.org/10.1037/a0026223

Hulleman, C. S., Schrager, S. M., Bodmann, S. M., \& Harackiewicz, J. M. (2010). A meta-analytic review of achievement goal measures. Psychological Bulletin, 136, 422-449. https://doi.org/10.1037/a0018947

Jaitner, D., Rinas, R., Becker, C., Niermann, C., Breithecker, J., \& Mess, F. (2019). Supporting subject justification by educational psychology. Frontiers in Education, 4, 70. https://doi.org/10.3389/feduc.2019.00070

Janke, S., \& Dickhäuser, O. (2018). A situated process model of vocational achievement goal striving within members of the academic staff at university. Motivation and Emotion, 42, 466-481. https://doi.org/10.1007/s11031-017-9657-z

Kaplan, A., \& Maehr, M. L. (2007). The contributions and prospects of goal orientation theory. Educational Psychology Review, 19, 141-184. https://doi.org/c35zn6

Kavussanu, M., Morris, R. L., \& Ring, C. (2009). The effects of achievement goals on performance, enjoyment, and practice of a novel motor task. Journal of Sports Science, 27, 1281-1292. https://doi.org/10.1080/02640410903229287

Keetch, K. M., \& Lee, T. D. (2007). The effects of self-regulated and experimenter-imposed practice schedules on motor learning for tasks of varying difficulty. Research Quarterly for Exercise and Sport, 78, 476-486.

King, R. B., \& McInerney, D. M. (2014). The work avoidance goal construct. Contemporary Educational Psychology, 39, 42-58. https://doi.org/10.1016/j.cedpsych.2013.12.002

Korn, R. M., Elliot, A. J., \& Daumiller, M. (2019). Back to the roots. Learning and Individual Differences, 72, 92102. https://doi.org/10.1016/j.lindif.2019.04.009

Lewthwaite, R., \& Wulf, G. (2012). Motor learning through a motivational lens. In N. Hodges, \& A. Williams (Eds.), Skill acquisition in sport (pp. 173-190). Routledge.

Lochbaum, M., Jean-Noel, J., Pinar, C., \& Gilson, T. (2017). A meta-analytic review of Elliot's (1999) Hierarchical Model of Approach and Avoidance Motivation in the sport, physical activity, and physical education literature. Journal of Sport and Health Science, 6, 68-80. https://doi.org/10.1016/j.jshs.2015.07.008

Lochbaum, M., \& Gottardy, J. (2015). A meta-analytic review of the approach-avoidance achievement goals and performance relationships in the sport psychology literature. Journal of Sport and Health Science, 4, 164-173. https://doi.org/f7rcvv

Lochbaum, M., Zanatta, T., \& Kazak, Z. (2020). The $2 \times 2$ achievement goals in sport and physical activity contexts. European Journal of Investigation in Health, Psychology and Education, 10, 173-205. https://doi.org/10.3390/ejihpe10010015 
Mascret, N., Elliot, A. J., \& Cury, F. (2015). Extending the $3 \times 2$ achievement goal model to the sport domain. Psychology of Sport and Exercise, 17, 7-14. https://doi.org/10/f62px6

Morris, R. L, \& Kavussanu, M. (2009). The role of approach-avoidance versus task and ego goals in enjoyment and cognitive anxiety in youth sport. International Journal of Sport and Exercise Psychology, 7, 185-202. https://doi.org/10.1080/1612197X.2009.9671899

Murayama, K., Elliot, A. J., \& Friedman, R. (2012). Achievement goals. In R. Ryan (Ed.), The Oxford handbook of human motivation (pp. 191-207). Oxford University.

Murayama, K., Goetz, T., Malmberg, L.-E., Pekrun, R., Tanaka, A., \& Martin, A. J. (2017). Within-person analysis in educational psychology. In D. Putwain, \& K. Smart (Eds.), Psychological Aspects of Education Current Trends (pp. 71-87). Wiley.

Muthén, L., \& Muthén, B. (2017). Mplus (version 8.1) [Computer Software]. Los Angeles, CA: Muthén \& Muthén.

Ntoumanis, N., \& Biddle, S. J. (1999). Affect and achievement goals in physical activity. Scandinavian Journal of Medicine and Science in Sports, 9, 333-343.

Nunnally, J., \& Bernstein, I. (1994). Psychometric theory (3rd ed.). McGraw-Hill.

Palmer, K. K., Chinn, K. M., \& Robinson, L. (2017). Using achievement goal theory in motor skill instruction. Sports Medicine, 47, 2569-2583. https://doi.org/gentvx

Payne, S., Youngcourt, S., \& Beaubien, J. (2007). A metaanalytic examination of the goal orientation nomological net. Journal of Applied Psychology, 92, 128-150.

Pintrich, P. R. (2000). The role of goal orientation in selfregulated learning. In M. Boekaerts, P. R. Pintrich, \& M. Zeidner (Eds.), Handbook of self-regulation (pp. 451-502). Academic. https://doi.org/10.1016/B978012109890-2/50043-3

Postmes, T., Haslam, S. A., \& Jans, L. (2013). A singleitem measure of social identification. British Journal of Social Psychology, 52, 597-617. https://doi.org/10.1111/bjso.12006

Praetorius, A.-K., Nitsche, S., Janke, S., Dickhäuser, O., Drexler, K., Fasching, M., \& Dresel, M. (2014). Here today, gone tomorrow. Contemporary Educational Psychology, 39, 379-387.

https://doi.org/10.1016/j.cedpsych.2014.10.002

Robins, R. W., Hendin, H. M., \& Trzesniewski, K. H. (2001). Measuring global self-esteem: Construct validation of a single-item measure and the Rosenberg SelfEsteem Scale. Personality and Social Psychology Bulletin, 27(2), 151-161.

Rotgans, J. I., \& Schmidt, H. G. (2011). Cognitive engagement in the problem-based learning classroom. $A d$ vances in Health Sciences Education, 16, 465-479.
Sage, L. D., \& Kavussanu, M. (2008). Goal orientations, motivational climate, and prosocial and antisocial behaviour in youth football. Journal of Sports Sciences, 26, 717-732.

Scherrer, V., \& Preckel, F. (2019). Development of motivational variables and self-esteem during the school career. Review of Educational Research, 89, 211-258.

Senko, C., \& Harackiewicz, J. M. (2005). Regulation of achievement goals. Journal of Educational Psychology, 97, 320-336. https://doi.org/10.1037/00220663.97.3.320

Senko, C., Hulleman, C. S., \& Harackiewicz, J. M. (2011). Achievement goal theory at the crossroads. Educational Psychologist, 46, 26-47. https://doi.org/bn7gt4

Shen, B., Chen, A., \& Guan, J. (2007). Using achievement goals and interest to predict learning in physical education. Journal of Experimental Education, 75, 89-108.

Skaalvik, E. M. (1997). Self-enhancing and self-defeating ego orientation. Journal of Educational Psychology, 89, 71-81. https://doi.org/10.1037/0022-0663.89.1.71

Stenling, A., Ivarsson, A., \& Lindwall, M. (2017). The only constant is change. International Review of Sport and Exercise Psychology, 10, 230-251. https://doi.org/f3rxfd

Stoeber, J., Stoll, O., Pescheck, E., \& Otto, K. (2008). Perfectionism and achievement goals in athletes. Psychology of Sport and Exercise, 9, 102-121. https://doi.org/10/btfnch

Van Hooff, M. L., Geurts, S. A., Kompier, M., \& Taris, T. W. (2007). "How fatigued do you currently feel?". Journal of Occupational Health, 49, 224-234. https://doi.org/bxw3tc

Van Yperen, N. W., Blaga, M., \& Postmes, T. (2014). A meta-analysis of self-reported achievement goals and nonself-report performance across three achievement domains. PLoS One, 9, e93594. https://doi.org/10.1371/journal.pone.0093594

Voelkle, M. C., Brose, A., Schmiedek, F., \& Lindenberger, U. (2014). Towards a unified framework for the study of between-person and within-person structures. Multivariate Behavioral Research, 49, 193e213. https://doi.org/10.1080/00273171.2014.889593

Wang, L. P., \& Maxwell, S. E. (2015). On disaggregating between-person and within-person effects with longitudinal data using multilevel models. Psychological Methods, 20, 63-83. https://doi.org/10.1037/met0000030

Warburton, V. E., \& Spray, C. M. (2017) Individual-level change in achievement goals in physical education. International Journal of Research Studies in Education, 6. 75-90. https://doi.org/10.5861/ijrse.2016.1418

Williams, L. (1998). Contextual influences and goal perspectives among female youth sport participants. $R e$ search Quarterly for Exercise \& Sport, 69, 47-57. https://doi.org/10/d4j4

Wright, A. G. C., \& Zimmermann, J. (2019). Applied ambulatory assessment. Psychological Assessment, 31, 1467-1480. https://doi.org/10.1037/pas0000685 
Yli-Piipari, S., Barkoukis, V., Jaakkola, T., \& Liukkonen, J. (2013). The effect of physical education goal orientations and enjoyment in adolescent physical activity. Sport, Exercise, and Performance Psychology, 2, 15-31. https://doi.org/10.1037/a002980

Zimmerman, B. J. (2000). Attaining self-regulation: A social-cognitive perspective. In M. Boekaerts, P. Pintrich, $\&$ M. Seidner (Eds.), Self-regulation: Theory, research, and applications (pp. 13-39). Academic Press.

Zimmerman, B. J. (2013). From cognitive modeling to selfregulation. Educational Psychology, 48, 135-147.

https://doi.org/10.1080/00461520.2013.794676

Zimmerman, B. J., \& Kitsantas, A. (1996). Self-regulated learning of a motoric skill. Journal of Applied Sport Psychology, 8, 69-84.

https://doi.org/10.1080/10413209608406308
Zimmerman, B. J., \& Kitsantas, A. (1998). Self-regulation of motoric learning. Journal of Applied Sport Psychology, 10, 220-239. https://doi.org/10.1080/10413209808406390

Zimmerman, B. J., \& Schunk, D. H. (2008). Motivation. In D. H. Schunk, \& B. J. Zimmerman (Eds.), Motivation and self-regulated learning (pp. 1-30). Lawrence Erlbaum.

Note. This is a pre-copyedited, author-produced PDF of an article accepted for publication in Sport, Exercise, and Performance Psychology following peer review. This paper is not the copy of record and may not exactly replicate the final, authoritative version of the article. The final article will be available, upon publication, via its DOI. 